\title{
Periostin: a predictable molecule to prognosis and chemotherapy responses of gastrointestinal and hepato-biliary-pancreatic malignant tumors?
}

\author{
Minireview
}

Wei ZHANG ${ }^{1,2, *}$, Fa-Hong WU ${ }^{1, *}$, Jia WANG ${ }^{1}$, Hang-Zhi WEI ${ }^{1}$, Tian-Wei WANG ${ }^{1}$, You-Cheng ZHANG ${ }^{1, *}$

${ }^{1}$ Department of General Surgery, Hepatic-biliary-pancreatic Institute, Second Hospital of Lanzhou University, Lanzhou, Gansu, China; ${ }^{2}$ Lanzhou Hospital of Traditional Chinese Medicine, Lanzhou, Gansu, China

${ }^{*}$ Correspondence: zhangychmd@126.com

"Contributed equally to this work.

Received October 25, 2021 / Accepted December 29, 2021

\begin{abstract}
With the continuous development of medical science and technology, the medical community's understanding of the disease is constantly updated, just as strategies for treating malignant tumors are constantly updated. New diagnoses, followup indicators, and treatment plan formulations need more evidence to be supported. To date, radical surgical resection is still the preferred treatment for advanced digestive system malignancies, and combination therapy including chemotherapy and targeted therapy before or after surgery is aimed at improving the prognosis and quality of life of patients. However, if tumor recurrence, metastasis, chemotherapy, and drug resistance to targeted agents after surgery prevent the achievement of the desired therapeutic effect, and if neoadjuvant chemotherapy and targeted therapy cannot reduce the staging of the tumor, surgery cannot be performed. These are huge problems that we face now and will continue to face for some time. Relevant scientific data and evidence have been produced to explain unsatisfactory efficacy, such as epithelial-mesenchymal transformation, the tumor microenvironment, extracellular matrix proteins, cancer-related fibroblasts, and other factors that may be related to tumor progression and poor therapeutic effects. An extracellular matrix protein, periostin (POSTN), influences the above factors and has received multidisciplinary attention. In this paper, periostin and digestive systemrelated tumors are reviewed, and the production, mechanism of action, drug resistance correlation analysis, and coping strategies of periostin are summarized to further understand its characteristics. This work provides evidence for potential therapeutic targets for digestive system tumors in the future.
\end{abstract}

Key words: periostin (POSTN), microenvironment, drug resistance, prognosis marker, tumor

Malignant tumors of the digestive system have a high incidence worldwide and limited therapeutic effects. In clinical practice, both doctors and patients need a reliable marker to monitor tumor progression and, more importantly, a screening marker to predict the drug sensitivity of nonsurgical treatments (e.g., chemotherapy, targeted therapy, and immunotherapy). Markers that can be successfully used in clinical practice must meet two conditions: reproducibility and convenience.

Since the clinical introduction of targeted drugs, drug resistance has emerged for many types of targeted therapy drugs, which urgently necessitates the identification of exact markers to guide drug use. Some scholars use gene sequencing to screen the sensitivity of targeted drugs to develop individualized treatment plans $[1,2]$. Others have also analyzed and screened sensitive markers from the perspective of intestinal microorganisms to ensure the effective application of immune checkpoint inhibitors in patients with gastric cancer [3]. Additionally, scholars have developed individualized targeted drug therapies for patients with positive connections and achieved safe and effective antitumor results [4]. These scientific efforts illustrate one point, that is, the existing targeted therapies and immunotherapies are not yet able to achieve precise and individualized treatment and can only 
benefit some patients. Reviewing traditional chemotherapy, there is also the problem of tumor insensitivity to chemotherapy drugs, which urgently needs to be solved. In recent years, an increasing number of studies have investigated the influence of the tumor microenvironment, cells and extracellular matrix on tumorigenesis, development and outcome, which may help guide the work of clinicians and benefit patients more. According to this review, periostin (POSTN), a specific extracellular matrix protein, may be valuable in the clinical treatment and prognosis of some digestive system tumors.

The extracellular matrix (ECM) is important for the normal structure and function of connective tissues. Secreted by local cells, the ECM provides physical support to cells, tissues, and organs. POSTN is a $90 \mathrm{kDa}$ disulfide-linked protein belonging to the fasciclin family and insect fasciclin I, which has remarkable structural homology. Moreover, from the molecular point of view, POSTN from different tissue sources has different subtypes. However, all of these subtypes can be regulated by transforming growth factor $\beta$ (TGF- $\beta$ ) $[5,6]$. POSTN has an important role in regulating the inflammatory and tumor microenvironments [7].

POSTN, a secreted protein from the extracellular matrix, has been proven to be related to tumor development and prognosis in some malignant tumor studies. The role of the tumor microenvironment in tumor progression has been widely recognized. The tumor microenvironment includes not only cellular components such as immune cells, fibroblasts, and endothelial cells, as well as malignant tumor cells themselves, but also noncellular components, such as the ECM [8] and cancer-promoting stromal factors [9]. POSTN is considered an independent factor associated with malignancy progression, is associated with patient OS, and can also be used as a marker for tumors of epithelial origin [10]. Data from trials involving the Notch signaling pathway in the differentiation of hepatocellular precursors and hepatocellular carcinoma suggest that POSTN may be a reliable prognostic biomarker and a potential therapeutic target in human solid carcinoma [11]. Research on the hypothesis of tumor resistance to antiangiogenic drugs has suggested that a) high levels of POSTN promote tumor angiogenesis; b) POSTN improves cancer cell survival under hypoxic conditions; and c) genetic modulation of POSTN induces epithelial-mesenchymal transition (EMT) and enhances cancer cell invasion and metastasis, which represents an escape mechanism from anticancer treatment [12].

\section{Gastric cancer (GC)}

The overexpression of POSTN was observed in GC tissues and metastatic lymph nodes, suggesting that the POSTN protein plays an important role in the progression and metastasis of GC [13]. This may be caused by PI3 kinase-Akt activation and thus increase tumor cell invasion (Figure 1) [14]. POSTN was expressed in the stroma of primary gastric tumors and metastases but not in normal gastric tissue and was closely related to the expression of $\alpha$-smooth muscle actin (SMA). Isoproterenol upregulates the expression of POSTN

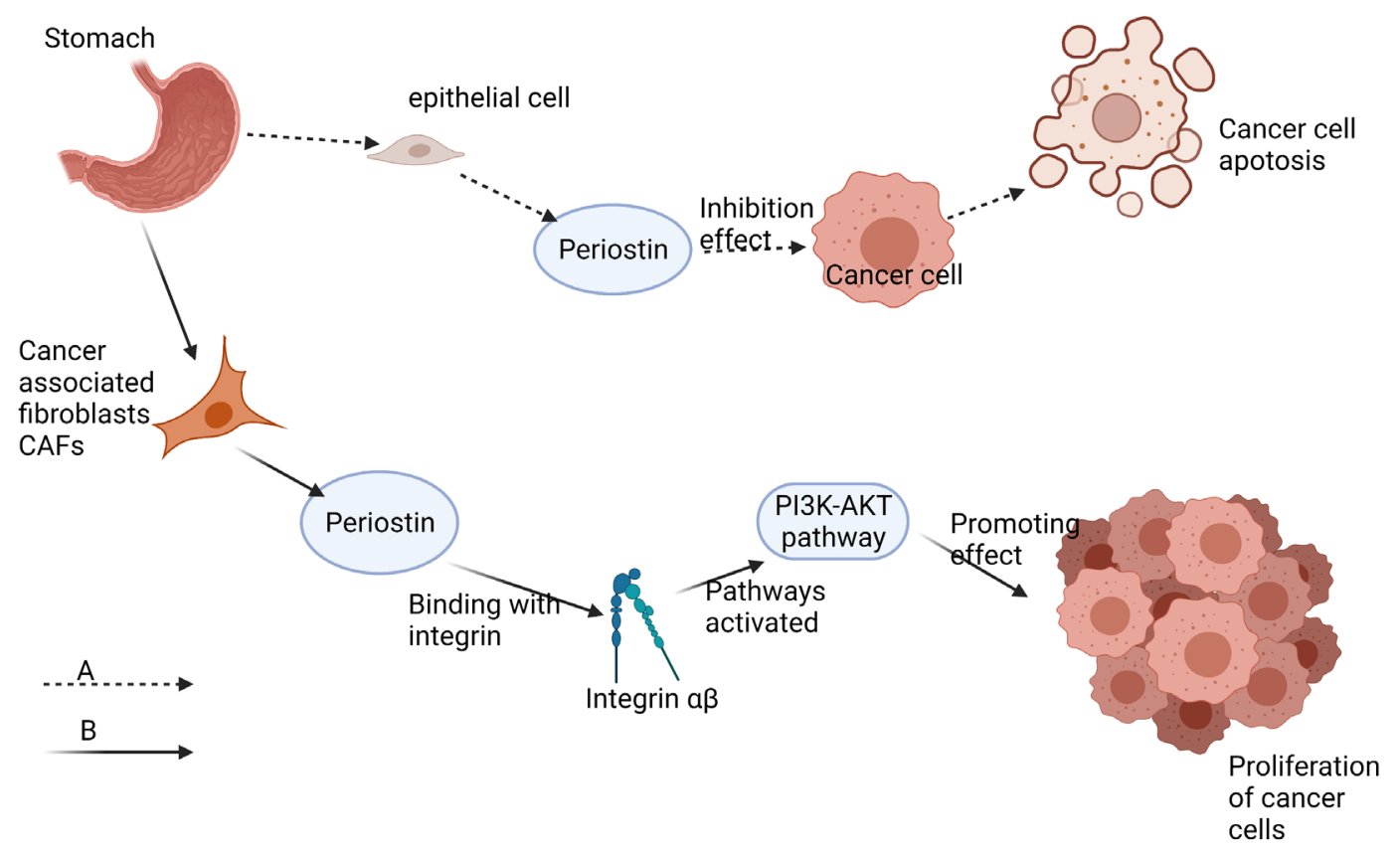

Figure 1. Different sources of POSTN in gastric cancer determine the biological characteristics of POSTN. A) POSTN from epithelial cells has an inhibitory effect on cancer. B) POSTN from the extracellular matrix (ECM) and cancer-related fibroblasts promotes the growth and invasion of cancer tissues. 
in GC cells [15]. Nicotine upregulates POSTN in GC cells through a cyclooxygenase-2 (COX-2)-dependent pathway, which is blocked by the COX-2-specific inhibitor NS398. POSTN-silenced gastric cancer cells exhibited reduced cell proliferation, elevated sensitivity to chemotherapy with 5 -fluorouracil, and decreased cell invasion and Snail expression $(\mathrm{p}<0.05)$. POSTN is a nicotine target gene in GC and plays a role in GC cell growth, invasion, drug resistance, and EMT facilitated by nicotine [16]. The regulatory effect of nicotine has also been found in other malignancies, which cannot be blocked by specific nicotinic receptor blockers, and the mechanism of its resistance to cisplatin has been confirmed [17]. Western blot analysis showed that the time-dependent induction of POSTN in MKN-45 cells was increased 8-fold compared with that in normoxic cells with the upregulation of hypoxia-inducible factor- $1 \alpha$ under hypoxia $\left(2 \% \mathrm{O}_{2}\right)$. In addition, the loss of POSTN protein significantly reduced the mRNA expression and secretion of vascular endothelial growth factor (VEGF) in hypoxic MKN-45 cells. Therefore, it can be inferred that POSTN is a hypoxic-response gene that mediates crosstalk between GC and endothelial cells under hypoxic conditions, partly by regulating VEGF expression [18]. A cell assay (3-(4,5-dimethylthiazole-2-yl)2,5-diphenyltetrazole bromide assay) showed that POSTN had no effect on the proliferation of gastric cancer cells (SGC-7901). Compared with empty vector-transfected cells, POSTN overexpression caused SGC-7901 cells to become more resistant to cisplatin- or 5-fluorouracil (5-FU)-induced apoptosis, with less mitochondrial cytochrome $\mathrm{C}$ release and reduced caspase- 3 and poly (ADP-ribose) polymerase cleavage. Pretreatment of POSTN-overexpressing cells with the Akt inhibitor MK-2206 partially saved POSTNmediated inhibition of p53 expression and drug resistance. These data suggest that POSTN has a protective effect against cisplatin- or 5-FU-induced apoptosis of SGC-7901 cells, possibly by regulating the Akt/p53 pathway, thus allowing it to become a potential therapeutic target for gastric cancer [19]. The current staging of gastric cancer cannot predict the prognosis of stage II and III GC alone and the benefits of adjuvant chemotherapy. Tumor immune microenvironment biomarkers and tumor cell chemical sensitivity may increase the predictive value of staging. The study of the tumor micro-environment and comprehensive evaluation methods may benefit patients in choosing chemotherapy regimens [17]. There are overlapping components in the treatment of breast cancer and GC, such as HER2-targeted therapy and gemcitabine drug chemotherapy. Citing breast cancer-related studies, gemcitabine resistance occurs within a few weeks, which may be related to tumor heterogeneity and the influence of the tumor microenvironment. However, POSTN was found to be a key factor in epithelial-mesenchymal transformation (EMT)-dependent chemotherapy in a trial [20].

Bioinformatics methods were used to explore the relationship between POSTN and the GC microenvironment. Then, through cell, animal, and human sample testing, it was found that POSTN is related to the occurrence and development of GC through the ERK pathway and may also promote EMT [21]. However, based on the understanding of cancerassociated fibroblasts in the academic community, the source of POSTN still needs to be discussed [22]. Other observations suggest that POSTN derived from different types of cells may play distinct biological roles in gastric tumorigenesis. As mentioned above, an experiment investigating the source and function of POSTN was conducted. POSTN derived from GC cells was identified by in situ hybridization. Further tests showed that POSTN derived from gastric cancer cells could inhibit the proliferation and invasion of cancer cells and promote the apoptosis of tumor cells at the same time (Figure 1A). It stabilizes p53 and E-cadherin proteins through the $\mathrm{Rb} / \mathrm{E} 2 \mathrm{~F} 1 / \mathrm{p} 14(\mathrm{ARF}) / \mathrm{MDM} 2$ signaling pathway and exhibits tumor-suppressive activity in GC [23]. In contrast, POSTN from cancer-associated fibroblasts exhibits obvious effects by promoting tumor growth and metastasis (Figure 1B). At present, the molecular characterization of malignant ascites is particularly limited in cases of GC. Gastriscin and POSTN, which can distinguish malignant ascites from benign ascites, were verified by ELISA [24]. POSTN expression gradually increased with an increase in the NIH classification risk level, which was closely related to disease-free survival and overall survival. The expression of POSTN protein in GC tissues and metastatic foci was significantly higher than that in adjacent normal gastric mucosa tissues by immunohistochemistry and western blot. In addition, the expression of POSTN in advanced GC tissues was higher than that in early GC tissues. The current results confirm the significance of POSTN in driving gastric tumorigenesis and metastasis and suggest its potential use as a diagnostic or prognostic biomarker, as well as a candidate therapeutic target [25]. In light of the above evidence, POSTN is a very promising diagnostic and prognostic marker. According to Kii et al.s theory, POSTN in the blood is attributable to the increase in vascular permeability (hyperpermeability) caused by the initial tumor stage or inflammatory factors, POSTN in its free form is detected and captured, and serum POSTN can be used as a biomarker to detect tumors, inflammation, fibrosis, and allergies [26]. However, if the source of POSTN cannot be accurately distinguished, serological tests are not used to determine tumor prognosis. More clinical trials are needed to demonstrate the value of serological tests.

\section{Esophageal cancer (EC)}

In early experiments, gene detection at the mRNA and protein levels confirmed POSTN overexpression in esophageal squamous cell carcinoma (ESCC), which may be related to the communication between cells and ECM [27]. Subsequent studies in organotypic (three-dimensional) cell models and microarray experiments further confirmed its strong association with tumor cell migration and invasion in 
ESCC $[28,29]$. Another clinical trial also demonstrated that the upregulated rate of POSTN had a significant correlation with lymph node metastasis, adventitia invasion, and TNM stage [30]. Research on the specific mechanism by which it promotes the migration and invasion of ESCC has gradually developed. First, POSTN is an important factor for the adhesion of tumor cells and enables tumor cells to adhere and migrate [29]. Moreover, it is very important that POSTN expression is positively correlated with VEGF expression, which may determine the number and capacity of new blood vessels directly regulated by VEGF [31]. Related to the specific effect pathway of ESCC, POSTN cooperates with mutant p53 to mediate invasion through the induction of STAT1 signaling in the esophageal tumor microenvironment (Figure 2A) [32]. Conversely, in the study of esophageal adenocarcinoma (EAC), paracrine interaction between CAF-secreted POSTN and EAC-expressed integrins results in PI3 kinase-Akt activation and increased tumor cell invasion (Figure 2B) [14]. A recent retrospective study found that the expression of inflammation-related factors such as the neutrophil-lymphocyte ratio (NLR), platelet-lymphocyte ratio (PLR), and C-reactive protein (CRP)-albumin ratio (CAR) in ESCC was directly related to POSTN [33]. Evidence suggests that POSTN is an independent prognostic factor in ESCC $[31,34,35]$. Since POSTN has been proven to be of prognostic and diagnostic value, the clinical application of related research is gradually being carried out, and the results are exciting. The practical value of POSTN combined with radionuclide-related examination and PET-CT is expected to be applied in clinical diagnosis and treatment $[36,37]$.

\section{Liver and biliary system-related malignancies}

There is evidence that the interaction of hepatocellular carcinoma (HCC) with activated hepatic stellate cells promotes tumorigenicity, growth, migration, invasion, angiogenesis, and metastasis of $\operatorname{HCC}[38,39]$. In addition, the interaction between the extracellular matrix and cells and changes in the microenvironment are key factors in the development and progression of tumors [40]. In vivo injection of active hepatic stellate cells (HSCs) into tumor-carrying mice showed that HSCs could produce POSTN protein, which promoted the tumor progression of residual hepatocellular carcinoma after heat treatment. The process was inhibited by a vitamin $\mathrm{D}$ analog calcipotriol. The chemotherapy regimen consisting of calcitriol combined with cisplatin can prevent the accelerated progression of residual HCC after suboptimal heat treatment [41]. Another experiment also confirmed that POSTN regulated residual HCC cells after heat treatment through the integrin $\beta 1 /$ Akt/GSK-3 $\beta / \beta$-catenin/TCF4/ Nanog pathway. The integrin $\beta 1$-mediated secondary pathway can be blocked by metformin [42]. Recent studies have also confirmed that metformin can reduce vascular calcification through the regulation of POSTN, P53, and other factors to produce anti-ferroptosis effects [43]. In hepatic metastasis of pancreatic ductal cell carcinoma, it was found that early inflammatory cell infiltration, such as granulin, monocytes, and metastasis-associated macrophages, could activate HSCs to secrete POSTN, thus creating a fibrotic microenvironment to support the growth of metastatic carcinoma tissue (Figure 3B) [44]. Sulfatase 2 is secreted in the paracrine

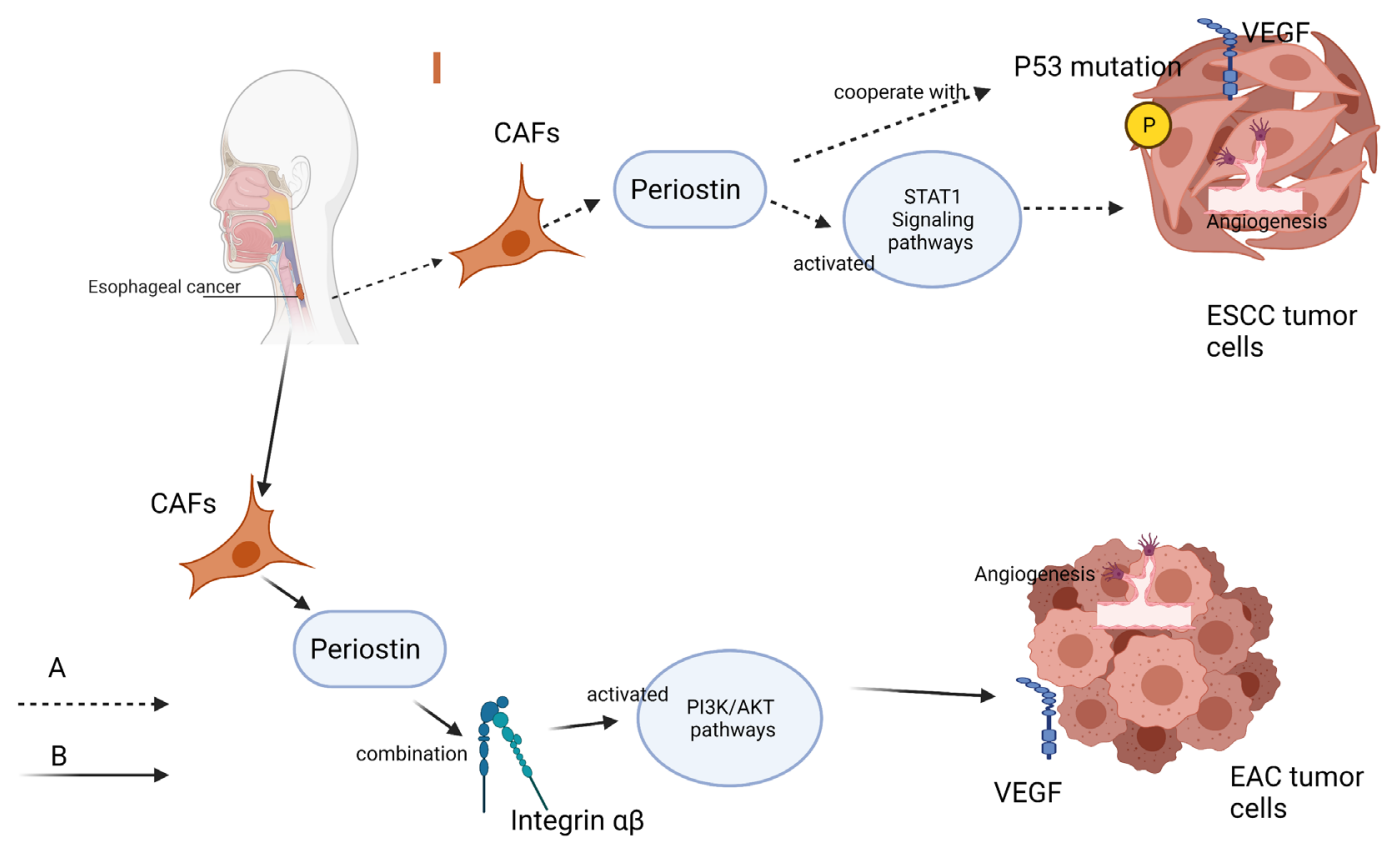

Figure 2. The occurrence and development of different pathological types of esophageal carcinoma are related to POSTN. A) Squamous cell carcinoma is formed through the combined action of the STAT1 pathway and P53 mutation. B) Formation of adenocarcinoma through the activation of the PI3K/ AKT pathway by binding integrin. 


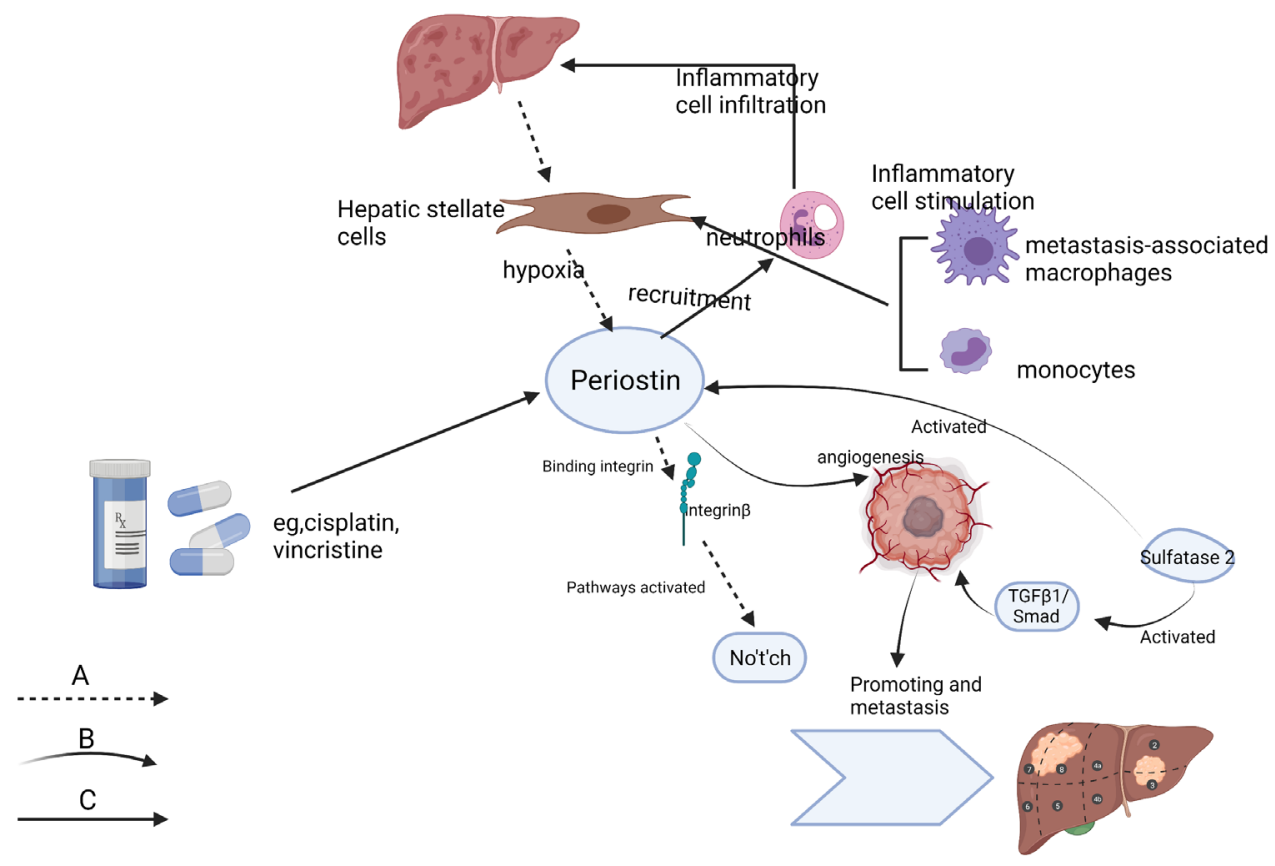

Figure 3. The origin of POSTN in the liver and its relationship with inflammatory cells. A) Hepatic stellate cells produce POSTN under hypoxic conditions, and POSTN binds integrin $\beta$ to promote hepatocellular carcinoma progression and metastasis through the Notch pathway. B) Inflammatoryrelated cells include monocytes, macrophages, neutrophils, etc. Hepatic stellate cells are stimulated to produce POSTN and then promote tumor progression and metastasis through the pathway (A). C) Chemotherapeutic agents such as cisplatin and vincristine can lead to increased POSTN secretion, liver fibrosis, and neutrophil aggregation, eventually initiating pathway (A).

form in human HCC, and its overexpression can increase endothelial cell proliferation, adhesion, chemotaxis, and tube formation. In vivo studies found that sulfatase 2 affected angiogenesis through the TGF $\beta 1 /$ Smad pathway and POSTN protein, and POSTN was the key effector protein. Sulfatase 2 knockout mice significantly reduced micro angiogenesis compared with non-knockout mice. In clinical specimens, it was found that the level of sulfate esterase 2 was positively correlated with the density of microvessels and the expression level of POSTN and negatively correlated with the prognosis of patients. The TGF $\beta 1 /$ Smad pathway is an important signal transmission axis between sulfatase 2 and the upregulation of POSTN transcription (Figure 3A), which has the potential to target anti-angiogenic therapy [45]. Arsenic trioxide is used in traditional Chinese medicine to treat malignant tumors. In the in vitro test, the expression of POSTN in tissues was first induced under hypoxic conditions, and its overexpression caused resistance to arsenic trioxide. Moreover, interestingly, after the expression of POSTN was reduced, tissue cells were again sensitive to arsenic trioxide. Notably, downregulation of POSTN significantly enhanced the anticancer effect of arsenic trioxide on SMMC7721 tumors and reduced the proportion of Ki-67-positive proliferating cells. Targeting POSTN may be a promising strategy to enhance arsenic trioxide anticancer therapy for liver cancer [46]. Recent bioinformatics analyses suggest that both miR-876 and POSTN are risk factors for HCC survival, and patients with low miR-876 expression and high POSTN expression have a worse prognosis. miR-876 inhibited HCC EMT and fibrosis by targeting POSTN, thereby affecting HCC progression and prognosis. miR-876 and POSTN may be useful therapeutic targets or prognostic markers for HCC [47]. Another study demonstrated that the combined assessment of POSTN protein overexpression and microvascular invasion in HCC is associated with poor prognosis and can be used as a good prognostic marker for HCC [48]. The postoperative median survival time and 3-year survival rate of HCC patients with high POSTN expression were significantly lower than those of the low POSTN expression group (10.00 months, 44.44\%; 59.00 months, $53.13 \%, \mathrm{p}=0.0312$ ). POSTN is related to the pathological process of the metastasis and invasion of liver cancer and may promote the migration and invasion of liver cancer cells. It is expected to be an important prognostic biomarker for tumor recurrence after HCC surgery and a therapeutic target for inhibiting metastasis [49]. Animal experiments showed that cisplatin increased the mRNA levels of matrix metalloproteinase (MMP-2) and POSTN in liver tissue, and vincristine also increased the mRNA levels of MMP-9 in liver tissue. According to histological and immunohistochemical analyses, cisplatin induced liver fibrosis, while vincristine induced neutrophil recruitment in liver tissue. In addition, increased mRNA expression of MMP-2 and POSTN after cisplatin or vincristine pretreatment may lead to fibrosis or neutrophil recruitment, respec- 


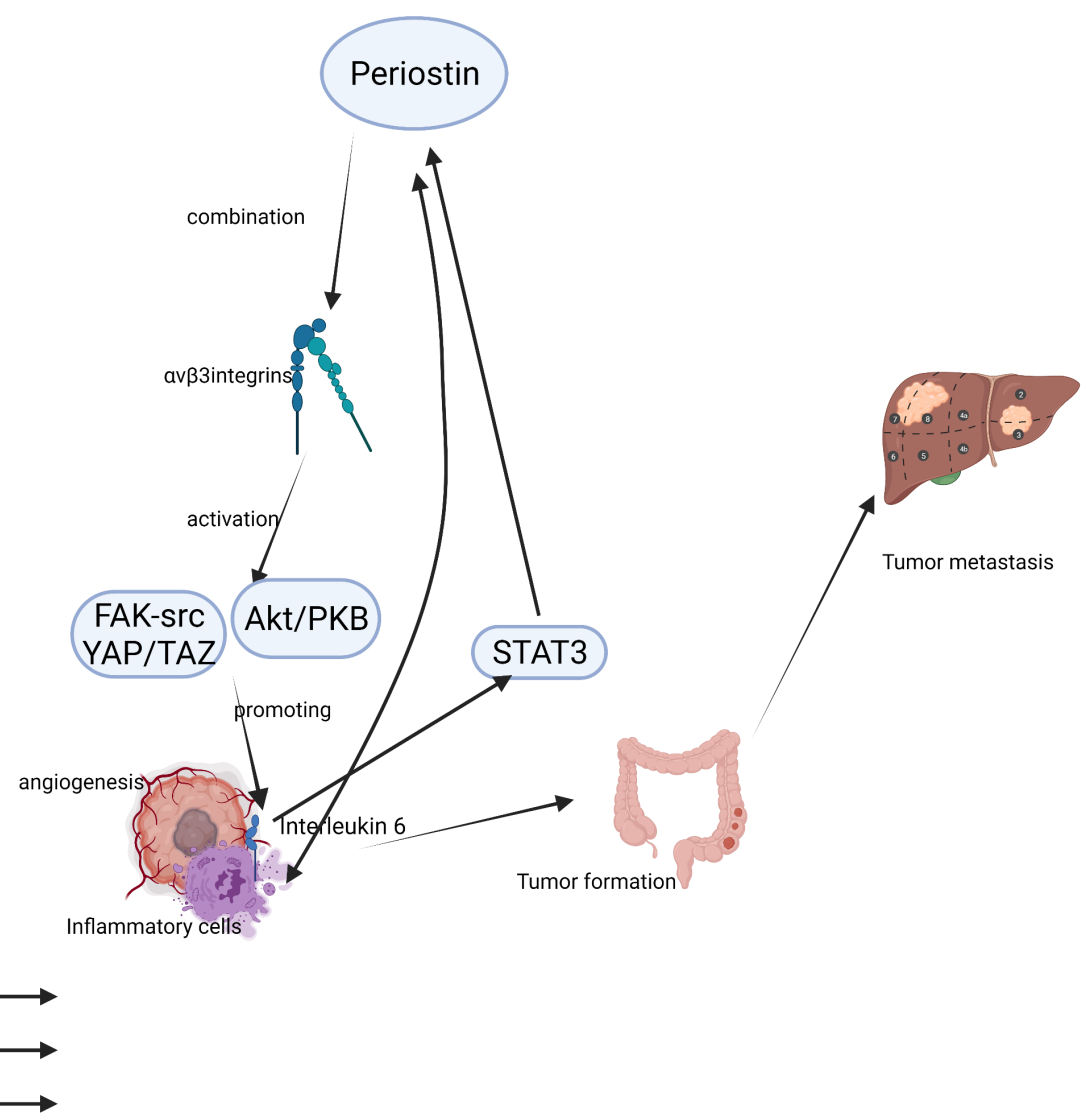

Figure 4. Role of POSTN in colorectal cancer. A, B) Colitis-related colorectal cancer, interleukin 6 can stimulate the extracellular matrix to produce POSTN through the STAT3 pathway. POSTN also activates the FAK-SRC and YAP/TAZ pathways by binding integrins to tumor growth, and interleukin-6 is present in tumor tissue. C) At the molecular level, POSTN increases cell survival by activating the Akt/PKB signaling pathway through the $\operatorname{\alpha v} \beta$ (3) integrin.

tively (Figure 3C). These niche factors may be associated with increased liver metastasis [50]. However, experiments have shown that the secreted protein POSTN is expressed to varying degrees in both primary cancer and liver metastasis, although the final statistical analysis showed that POSTN expression was not significantly associated with metastatic disease accompanying pancreatic ductal adenocarcinoma [35]. In patients with HCC, it was found that serum POSTN levels in advanced HCC patients were significantly higher than those in early HCC or healthy subjects, which was further confirmed by mRNA levels. In a subsequent experiment, the Notch pathway was found to exert a direct regulatory effect on POSTN [51]. Importantly, POSTN expression was found to be an independent predictor of overall and disease-free survival for HCC. The expression level of POSTN in HCC may be related to tumor metastatic potential and angiogenesis. Its abnormal expression can be used as a predictor of postoperative prognosis in patients with HCC [52]. There have also been trials to prove the diagnostic significance of serum POSTN: preoperative serum POSTN has limited diagnostic value in HCC and nonmalignant liver disease, but it can be used as an independent prognostic biomarker for HCC patients [53]. However, in early trials, both from a genetic and an immunohistochemical perspective, POSTN has important diagnostic value in the differentiation of bile duct cell malignancies and is also an important factor in predicting the poor prognosis of bile duct cell malignancies [54, 55]. A similar observation was made in bile duct carcinoma [56].

\section{Colorectal cancer}

POSTN is a cancer-promoting molecule of colon cancer. Inhibition of POSTN expression can increase the apoptosis rate of colon cancer cells and inhibit EMT. The expression and function of POSTN are regulated by the let-7a/ miR-98 family [57]. A new method based on categorizing the desmoplastic reaction (DR) showed that POSTN may be a key molecule in the production of colorectal cancer. POSTN expression was closely associated with DR categorization [58]. Similarly, a clinical trial showed that POSTN overexpression in the stroma of colorectal cancer was 
inversely associated with 5-year survival [59]. Studies of genomic heterogeneity in the microenvironment of primary colorectal cancer and liver metastases from colorectal cancer have identified selected genes that may lead to new diagnostic and therapeutic targets, including POSTN [60]. A large body of evidence shows that integrin receptors are closely involved in tumor formation and development, as well as cell migration and survival [61-63]. Specific blockade of some integrin receptors, such as $\alpha \mathrm{V} \beta 3$, can inhibit tumor metastasis (Figure 4C) [64]. POSTN expression significantly promoted metastatic growth of colon cancer by preventing stress-induced apoptosis and enhancing endothelial cell survival to promote angiogenesis. At the molecular level, POSTN increases cell survival by activating the Akt/PKB signaling pathway through $\alpha v \beta$ (3) integrin. The results of this trial reaffirm the strong association between the integrin receptor and POSTN in colorectal cancer [65]. Another type, colitis-related colorectal cancer, is derived from inflammatory bowel diseases such as ulcerative colitis and Crohn's disease. Increased POSTN protein expression is observed in the lamina propria in patients with colitis-associated colon cancer [66]. Studies on the pathogenesis of colorectal neoplasms caused by chronic inflammatory bowel disease have revealed that inflammatory mediators interact with POSTN to promote each other's production. Interleukin 6 can activate fibroblasts to secrete POSTN through the STAT3 pathway in chronic colorectal inflammation, and POSTN is activated through integrin-mediated outside-in signaling to activate FAK-Src kinases. This causes interleukin-6 to appear in the tumor. Such reciprocating interactions eventually lead to the formation of tumors (Figures 4A, 4B) [67]. Previous animal trials have shown contrasting results in vitro and in vivo, demonstrating that POSTN can inhibit the occurrence of colitis-related colorectal cancer [68]. Regarding the specific type of colorectal cancer associated with colitis, the relationship between POSTN and tumors still needs further study. However, based on dialectical thinking regarding commonness and personality, there may be a detailed connection between the commonness of POSTN carcinogenesis and the personality of cancer suppressants, which needs to be further understood and revealed. In the clinical application of differential diagnosis of tumors, POSTN also showed partial advantages at the beginning [69], though further studies are needed. POSTN creates an extracellular matrix environment that is conducive to tumor growth and promotes tumor growth and invasion and chemotherapy resistance. The effects of this invasion and resistance can be reduced by blocking the PI3K/Akt or Wnt/ $\beta$-catenin pathway [70-72]. Studies on chemotherapy resistance in colorectal cancer have shown that exosomes of 5-FU-resistant tumor cells can promote angiogenesis, and exosomal dipeptidyl peptidase IV (DPP4) is a powerful proangiogenic agent. Exosomes rich in DPP4 increase POSTN expression in human umbilical vein endothelial cells through nuclear translocation or activation of the Smad signaling pathway at Twist 1 , and silencing or suppression of DPP4 neutralizes

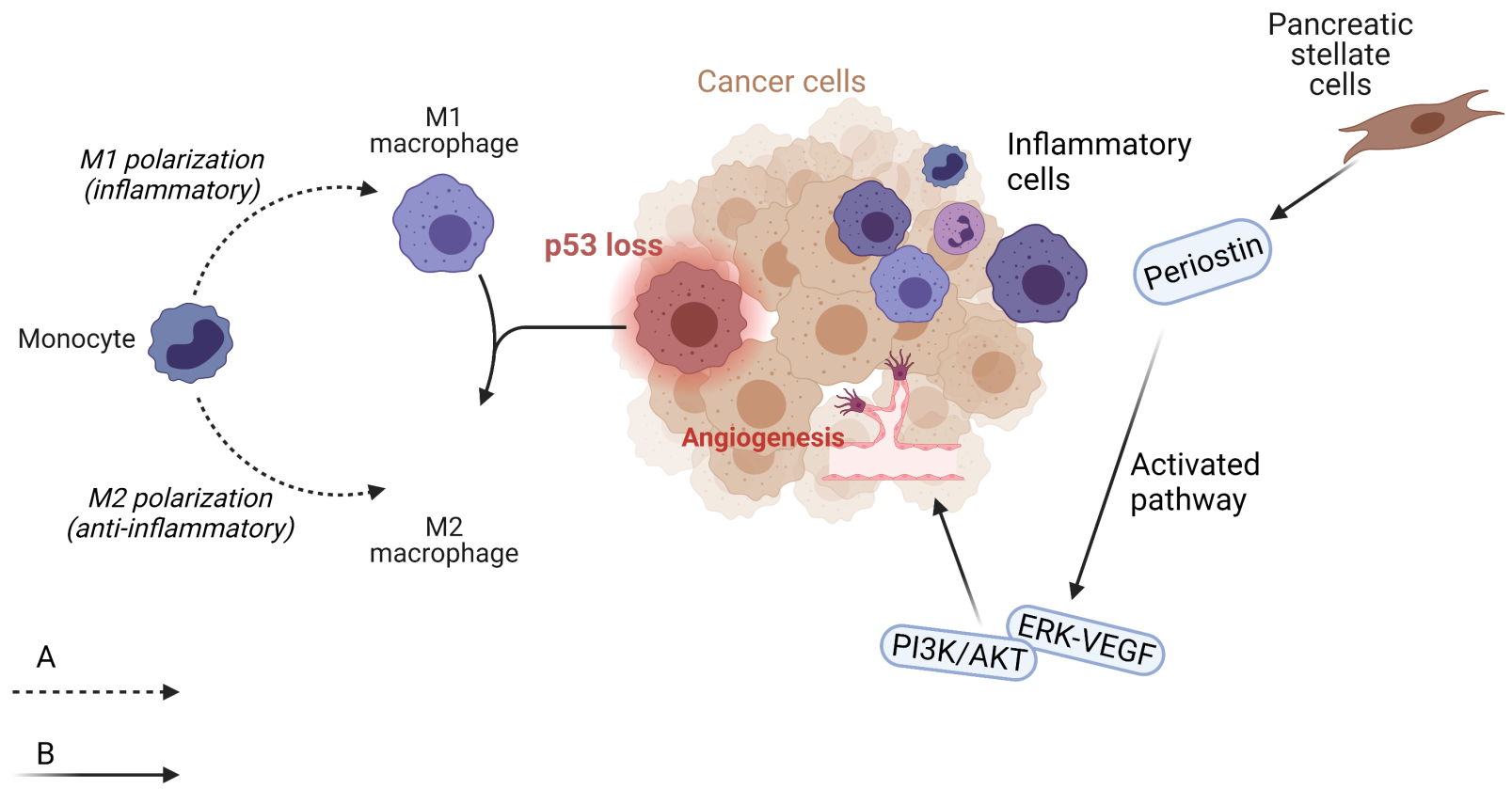

Figure 5. POSTN and pancreatic tumor formation. A) Monocytes differentiated into M1- and M2-type macrophages; M1 macrophages were associated with inflammation, and M2 macrophages were associated with tumorigenesis. B) Pancreatic stellate cells produce POSTN, and the combination of POSTN with integrin activates the ERK/VEGF pathway and PI3K/AKT pathway to promote the growth of new blood vessels, nourish tumor cells, and infiltrate inflammatory cells, including M2 macrophages. 
these effects. In vivo and clinical data showed that high DPP4 expression was associated with tumor progression. These findings suggest that DPP4 may be a target for inhibiting angiogenesis in 5-FU-resistant colon cancer [73]. Similarly, xenograft experiments proved that the key genes of angiogenesis include POSTN, and certain specific regulations promote angiogenesis [74]. POSTN activates the proliferation, migration and invasion of colon cancer cells through the receptor integrin/pAKT pathway, while autophagy is decreased. When the Akt pathway is specifically blocked, autophagy resumes. The expression of genes associated with epithelial-mesenchymal transformation was reduced [75].

\section{Pancreas-associated tumors}

Pancreatic stellate cells create a desmoplastic environment of cancerous tissues. Stellate cells secrete POSTN after stimulation (Figure 5B). POSTN expression was tested under extreme conditions, such as hypoxia, starvation, and radiation therapy. The results showed that POSTN was able to first tolerate hypoxia and starvation, was continuously expressed, and then, surprisingly, its expression was uninhibited under radiation therapy [76]. Among tumorassociated macrophages, M1-like macrophages are associated with inflammatory infiltration, M2-like macrophages promote angiogenesis and tumorigenesis [77] (Figure 5A). POSTN was not expressed at the early stage of pancreatic intraepithelial neoplasia. During the progression from intraepithelial neoplasia to ductal adenocarcinoma, the expression level of POSTN was gradually increased, and it was found that there was a close relationship between macrophages and pancreatic stellate cells. When the stellate cells were in a static state, they could be activated by coculture with macrophages. At the same time, macrophages increase the production of cytokines [78]. POSTN was also found to be closely associated with drug resistance in other tumor antiangiogenic therapy studies [79]. In pancreatic neuroendocrine tumors, POSTN may be used as a chemokine or survival factor for macrophages. In animal experiments, it was found that the expression of POSTN led to the aggregation of M2-like macrophages. POSTN was then found to be specifically positively associated with M2-like macrophage expression in untreated human pancreatic endocrine tumors $[44,80]$. In pancreatic intraductal papillary mucinous neoplasms (IPMNs), the histological grade of branch duct type (BD-IPMN) was positively correlated with the expression levels of alpha-smooth muscle actin ( $a$-SMA), POSTN, and galectin-1, and they could become new markers for determining the indications for surgery in BD-IPMNs [81]. One study suggested that POSTN and CA242 are potential diagnostic serum biomarkers complementing CA19.9 in the detection of early pancreatic cancer [82]. The expression level of POSTN was very low in normal pancreatic tissue, acute pancreatitis, and chronic pancreatitis with no specific differences, while specifically high expres- sion was found in pancreatic ductal adenocarcinoma tissue. It was then proven that the high expression of POSTN and other matrix proteins may have an inhibitory effect on tumor progression rather than always promoting effect progression [83]. Tumor growth and nutritional support are closely related to angiogenesis, and blocking angiogenesis may limit tumor growth and progression. In this case, a conceptual system associated with tumor formation is formed, namely, the angiogenic switch $[84,85]$. The angiogenic switch, the time at which a tumor becomes vascularized, is a critical step in tumor progression. POSTN was found in higher abundance when tumors began to be supplied with blood namely, vascularized [86]. In the study of pancreatic cancer, lentivirus infection and recombinant POSTN were used to regulate POSTN expression, and it was found that increased POSTN expression promoted tubule formation dependent on human umbilical vein endothelial cells. Additionally, POSTN promotes tumor angiogenesis through the ERK/ VEGF signaling [87]. POSTN was specifically expressed in pancreatic stellate cells (PSCs) and in the stroma of pancreatic ductal adenocarcinoma, creating a microenvironment that supported tumor growth. Both in vivo and in vitro, gemcitabine-induced apoptosis was increased when POSTN was silenced, providing evidence that POSTN not only drives the carcinogenic process itself but is also significantly associated with gemcitabine-induced apoptosis, suggesting that POSTN increases chemotherapeutic resistance to gemcitabine in pancreatic ductal adenocarcinoma. Resistance to gemcitabine in PDAC chemotherapy may be addressed by targeting POSTN [88]. The increased stiffness of the PDAC stroma leads to intratumoral hypo-vascularity and hypoxia, representing a physical barrier to chemotherapy access. Treatment targeting tumor-stromal tissue may improve the survival of patients with pancreatic ductal adenocarcinoma, which is very promising $[89,90]$. Recent trials have also demonstrated that POSTN plays an important role in the study of chemotherapy resistance in other cancers, such as breast cancer and ovarian cancer, where resistance to docetaxel can be specifically combined with POSTN peptides to solve the problem of drug resistance [20, 91, 92].

\section{Conclusion}

As mentioned above, different sources of POSTN in gastric cancer may have different biological functions, including tumor promotion or tumor suppression. Therefore, we proposed the hypothesis that the diagnostic and prognostic value of serum POSTN expression in gastric cancer requires further detailed studies. On the other hand, experimental evidence has shown the prognostic value of POSTN proteins in liver-related malignancies, colorectal cancer and pancreatic cancer, and more data are expected to support and validate this finding in the future. We explored the relationship of POSTN with angiogenesis and drug resistance in the 
Table 1. Shows the expression of POSTN in some digestive system malignancies and the mechanisms and types of drugs related to tumour chemotherapy and targeted therapy resistance.

\begin{tabular}{llll}
\hline POSTN level & Tumor type & Therapeutic correlation & Tumor correlation \\
\hline High level & Gastric cancer (GC) & Cisplatin or 5-fluorouracil drug resistance & $\begin{array}{l}\text { EMT } \\
\text { Angiogenesis }\end{array}$ \\
High level & Hepatocellular carcinoma (HCC) & $\begin{array}{l}\text { Residual HCC progression was blocked by metformin or calcitriol } \\
\text { combined with cisplatin } \\
\text { Inefficiency of VEGF targeting drugs }\end{array}$ & $\begin{array}{l}\text { Angiogenesis } \\
\text { Fibrosis }\end{array}$ \\
High level & Colorectal cancer (CRC) & 5-fluorouracil resistant & EMT \\
High level & Pancreatic ductal adenocarcinoma & Angiogenesis & Angiogenesis \\
& & Inefficiency of VEGF targeting drugs & \\
\hline
\end{tabular}

tumor microenvironment. POSTN is usually considered an oncogene in diverse human cancers, whereas it acts as a tumor suppressor in bladder cancer [93]. Baseline POSTN and POSTN responses appeared to be reliable surrogate markers to predict the chemotherapy response and survival in patients with advanced non-small-cell lung cancer [79]. Recent studies have shown that POSTN is a marker for the prognosis and diagnosis of solid tumors [11].

Integrins play an important role in angiogenesis, and the types of integrins expressed in stationary blood vessels and newly sprouted capillaries are different [94]. The molecular structure of POSTN has a domain that binds integrin, which may indicate that the structural characteristics of POSTN affect angiogenesis [95]. Furthermore, the interaction of POSTN with VEGF may facilitate the preparation of materials to promote angiogenesis, and activation of the pathway may recruit more vascular endothelial cells derived from in situ endothelial cells or from pluripotent stem cells derived from bone marrow [85]. POSTN acts as an intermediate mediator of angiogenesis. Furthermore, if the serological expression level has good specificity and sensitivity, then the appropriate serological level range needs to be further studied. Among the numerous studies on POSTN and solid tumors, studies involving chemotherapy drug resistance and the efficacy of targeted antiangiogenic drugs are exciting, and we see a promising new target and research direction to overcome dissatisfaction with therapeutic effects (Table 1). As predicted by some experts, research on the tumor microenvironment and cancer-related fibroblasts is bound to generate great breakthroughs in the next 10 years [22]. We pay close attention to POSTN because studies on this protein are closely related to clinical work. It is hoped that future studies can further explore and study its potential value and offer new hope for the treatment of tumors with new specific targets.

Acknowledgments: Supported by Science and technology projects in Cheng-guan District of Lanzhou City (2014-4-4) and Lanzhou city science and technology development guidance plan (No. 2019-ZD-71).

\section{References}

[1] KIM HS, LEE H, SHIN SJ, BEOM SH, JUNG M et al. Complementary utility of targeted next-generation sequencing and immunohistochemistry panels as a screening platform to select targeted therapy for advanced gastric cancer. Oncotarget 2017; 8: 38389-38398. https://doi.org/10.18632/oncotarget.16409

[2] WON E, BASUNIA A, CHATILA WK, HECHTMAN JF, CHOU JF et al. Efficacy of Combined VEGFR1-3, PDGF $\alpha / \beta$, and FGFR1-3 Blockade Using Nintedanib for Esophagogastric Cancer. Clin Cancer Res 2019; 25: 3811-3817. https:// doi.org/10.1158/1078-0432.CCR-18-3789

[3] SUNAKAWA Y, INOUE E, MATOBA R, KAWAKAMI H, SATO Y et al. DELIVER (JACCRO GC-08) trial: discover novel host-related immune-biomarkers for nivolumab in advanced gastric cancer. Future Oncol 2019; 15: 2441-2447. https://doi.org/10.2217/fon-2019-0167

[4] TÜRECI O, SAHIN U, SCHULZE-BERGKAMEN H, ZVIRBULE Z, LORDICK F et al. A multicentre, phase IIa study of zolbetuximab as a single agent in patients with recurrent or refractory advanced adenocarcinoma of the stomach or lower oesophagus: the MONO study. Ann Oncol 2019; 30: 1487-1495. https://doi.org/10.1093/annonc/mdz199

[5] HORIUCHI K, AMIZUKA N, TAKESHITA S, TAKAMATSU H, KATSUURA $M$ et al. Identification and characterization of a novel protein, periostin, with restricted expression to periosteum and periodontal ligament and increased expression by transforming growth factor beta. J Bone Miner Res 1999; 14: 1239-1249. https://doi.org/10.1359/ jbmr.1999.14.7.1239

[6] YUE H, LI W, CHEN R, WANG J, LU X et al. Stromal POSTN induced by TGF- $\beta 1$ facilitates the migration and invasion of ovarian cancer. Gynecol Oncol 2021; 160: 530-538. https:// doi.org/10.1016/j.ygyno.2020.11.026

[7] LIU AY, ZHENG H, OUYANG G. Periostin, a multifunctional matricellular protein in inflammatory and tumor microenvironments. Matrix Biol 2014; 37: 150-156. https://doi. org/10.1016/j.matbio.2014.04.007

[8] VENNING FA, WULLKOPF L, ERLER JT. Targeting ECM Disrupts Cancer Progression. Front Oncol 2015; 5: 224. https://doi.org/10.3389/fonc.2015.00224 
[9] ENGELMANN JC, AMANN T, OTT-RÖTZER B, NÜTZEL M, REINDERS Y et al. Causal Modeling of Cancer-Stromal Communication Identifies PAPPA as a Novel StromaSecreted Factor Activating NFkB Signaling in Hepatocellular Carcinoma. PLoS Comput Biol 2015; 11: e1004293. https:// doi.org/10.1371/journal.pcbi.1004293

[10] KUJAWA KA, ZEMBALA-NOŻYŃSKA E, CORTEZ AJ, KUJAWA T, KUPRYJAŃCZYK J et al. Fibronectin and Periostin as Prognostic Markers in Ovarian Cancer. Cells 2020; 9: 149. https://doi.org/10.3390/cells9010149

[11] YANG T, DENG Z, PAN Z, QIAN Y, YAO W et al. Prognostic value of periostin in multiple solid cancers: A systematic review with meta-analysis. J Cell Physiol 2020; 235: 2800 2808. https://doi.org/10.1002/jcp.29184

[12] WANG W, MA JL, JIA WD, XU GL. Periostin: a putative mediator involved in tumour resistance to anti-angiogenic therapy? Cell Biol Int 2011; 35: 1085-1088. https://doi. org/10.1042/cbi20110171

[13] LI JS, SUN GW, WEI XY, TANG WH. Expression of periostin and its clinicopathological relevance in gastric cancer. World J Gastroenterol 2007; 13: 5261-5266. https://doi. org/10.3748/wjg. v13.i39.5261

[14] UNDERWOOD TJ, HAYDEN AL, DEROUET M, GARCIA E, NOBLE F et al. Cancer-associated fibroblasts predict poor outcome and promote periostin-dependent invasion in oesophageal adenocarcinoma. J Pathol 2015; 235: 466-477. https://doi.org/10.1002/path.4467

[15] LIU GX, XI HQ, SUN XY, GENG ZJ, YANG SW et al. Isoprenaline Induces Periostin Expression in Gastric Cancer. Yonsei Med J 2016; 57: 557-564. https://doi.org/10.3349/ ymj.2016.57.3.557

[16] LIU Y, LIU BA. Enhanced proliferation, invasion, and epithelial-mesenchymal transition of nicotine-promoted gastric cancer by periostin. World J Gastroenterol 2011; 17: 2674 2680. https://doi.org/10.3748/wjg. v17.i21.2674

[17] WU SQ, LV YE, LIN BH, LUO LM, LV SL et al. Silencing of periostin inhibits nicotine-mediated tumor cell growth and epithelial-mesenchymal transition in lung cancer cells. Mol Med Rep 2013; 7: 875-880. https://doi.org/10.3892/ mmr.2013.1267

[18] QIU F, SHI CH, ZHENG J, LIU YB. Periostin mediates the increased pro-angiogenic activity of gastric cancer cells under hypoxic conditions. J Biochem Mol Toxicol 2013; 27: 364-369. https://doi.org/10.1002/jbt.21498

[19] LI B, WANG L, CHI B. Upregulation of periostin prevents P53-mediated apoptosis in SGC-7901 gastric cancer cells. Mol Biol Rep 2013; 40: 1677-1683. https://doi.org/10.1007/ s11033-012-2218-3

[20] NAKAZAWA Y, TANIYAMA Y, SANADA F, MORISHITA $\mathrm{R}$, NAKAMORI $S$ et al. Periostin blockade overcomes chemoresistance via restricting the expansion of mesenchymal tumor subpopulations in breast cancer. Sci Rep 2018; 8: 4013. https://doi.org/10.1038/s41598-018-22340-7

[21] KIKUCHI Y, KUNITA A, IWATA C, KOMURA D, NISHIYAMA $\mathrm{T}$ et al. The niche component periostin is produced by cancer-associated fibroblasts, supporting growth of gastric cancer through ERK activation. Am J Pathol 2014; 184: 859-870. https://doi.org/10.1016/j.ajpath.2013.11.012
[22] SAHAI E, ASTSATUROV I, CUKIERMAN E, DENARDO DG, EGEBLAD $M$ et al. A framework for advancing our understanding of cancer-associated fibroblasts. Nat Rev Cancer 2020; 20: 174-186. https://doi.org/10.1038/s41568-0190238-1

[23] LV H, LIU R, FU J, YANG Q, SHI J et al. Epithelial cellderived periostin functions as a tumor suppressor in gastric cancer through stabilizing $\mathrm{p} 53$ and E-cadherin proteins via the Rb/E2F1/p14ARF/Mdm2 signaling pathway. Cell Cycle 2014; 13: 2962-2974. https://doi.org/10.4161/15384101.201 4.947203

[24] JIN J, SON M, KIM H, KIM H, KONG SH et al. Comparative proteomic analysis of human malignant ascitic fluids for the development of gastric cancer biomarkers. Clin Biochem 2018; 56: 55-61. https://doi.org/10.1016/j.clinbiochem.2018.04.003

[25] ZHONG H, LI X, ZHANG J, WU X. Overexpression of periostin is positively associated with gastric cancer metastasis through promoting tumor metastasis and invasion. J Cell Biochem 2019; 120: 9927-9935. https://doi.org/10.1002/ jcb. 28275

[26] KII I. Practical Application of Periostin as a Biomarker for Pathological Conditions. Adv Exp Med Biol 2019; 1132: 195-204. https://doi.org/10.1007/978-981-13-6657-4_18

[27] KWON YJ, LEE SJ, KOH JS, KIM SH, KIM YJ et al. Expression patterns of aurora kinase B, heat shock protein 47 , and periostin in esophageal squamous cell carcinoma. Oncol Res 2009; 18: 141-151. https://doi.org/10.3727/096504009790217407

[28] CHAITIN H, LU ML, WALLACE MB, KANG Y. Development of a Decellularized Porcine Esophageal Matrix for Potential Applications in Cancer Modeling. Cells 2021; 10: 1055. https://doi.org/10.3390/cells10051055

[29] MICHAYLIRA CZ, WONG GS, MILLER CG, GUTIERREZ CM, NAKAGAWA $\mathrm{H}$ et al. Periostin, a cell adhesion molecule, facilitates invasion in the tumor microenvironment and annotates a novel tumor-invasive signature in esophageal cancer. Cancer Res 2010; 70: 5281-5292. https://doi. org/10.1158/0008-5472.Can-10-0704

[30] LUO JH, ZHOU J, GAO Y. Correlation between periostin and SNCG and esophageal cancer invasion, infiltration and apoptosis. Asian Pac J Trop Med 2013; 6: 516-519. https:// doi.org/10.1016/s1995-7645(13)60088-7

[31] WANG W, SUN QK, HE YF, MA DC, XIE MR et al. Overexpression of periostin is significantly correlated to the tumor angiogenesis and poor prognosis in patients with esophageal squamous cell carcinoma. Int J Clin Exp Pathol 2014; 7: 593 601.

[32] WONG GS, LEE JS, PARK YY, KLEIN-SZANTO AJ, WALDRON TJ et al. Periostin cooperates with mutant p53 to mediate invasion through the induction of STAT1 signaling in the esophageal tumor microenvironment. Oncogenesis 2013; 2: e59. https://doi.org/10.1038/oncsis.2013.17

[33] ISHIBASHI Y, TSUJIMOTO H. ASO Author Reflections: Local Periostin Expression and Systemic Immunoinflammatory Measures in Esophageal Cancer: A Single-Center, Retrospective Study. Ann Surg Oncol 2020; 27: 801-802. https:// doi.org/10.1245/s10434-020-08779-X 
[34] JIANG Q, CHEN J, ZHANG B, NIU J, HE Y. Prognostic Significance of Periostin and Mammalian Target of Rapamycin (mTOR) in Locally Advanced Esophageal Squamous Cell Carcinoma. Med Sci Monit 2017; 23: 3200-3208. https://doi. org/10.12659/msm.904992

[35] ISHIBASHI Y, TSUJIMOTO H, EINAMA T, MOCHIZUKI $\mathrm{S}$, KOUZU $\mathrm{K}$ et al. Correlation Between Immunoinflammatory Measures and Periostin Expression in Esophageal Squamous Cell Carcinoma: A Single-Center, Retrospective Cohort Study. Ann Surg Oncol 2021; 28: 1228-1237. https:// doi.org/10.1245/s10434-020-08765-3

[36] WONG GS, HABIBOLLAHI P, HEIDARI P, LEE JS, KLEINSZANTO AJ et al. Optical imaging of periostin enables early endoscopic detection and characterization of esophageal cancer in mice. Gastroenterology 2013; 144: 294-297. https://doi.org/10.1053/j.gastro.2012.10.030

[37] HEIDARI P, ESFAHANI SA, TURKER NS, WONG G, WANG TC et al. Imaging of Secreted Extracellular Periostin, an Important Marker of Invasion in the Tumor Microenvironment in Esophageal Cancer. J Nucl Med 2015; 56: 12461251. https://doi.org/10.2967/jnumed.115.156216

[38] COUlOUARN C, CORLU A, GLAisE D, GUÉNON I, THORGEIRSSON SS et al. Hepatocyte-stellate cell crosstalk in the liver engenders a permissive inflammatory microenvironment that drives progression in hepatocellular carcinoma. Cancer Res 2012; 72: 2533-2542. https://doi. org/10.1158/0008-5472.CAN-11-3317

[39] AMANN T, BATAILLE F, SPRUSS T, MÜHLBAUER M, GÄBELE E et al. Activated hepatic stellate cells promote tumorigenicity of hepatocellular carcinoma. Cancer Sci 2009; 100: 646-653. https://doi.org/10.1111/j.1349-7006.2009.01087.x

[40] MAZZOCCA A, DITURI F, LUPO L, QUARANTA M, ANTONACI S et al. Tumor-secreted lysophostatidic acid accelerates hepatocellular carcinoma progression by promoting differentiation of peritumoral fibroblasts in myofibroblasts. Hepatology 2011; 54: 920-930. https://doi.org/10.1002/ hep. 24485

[41] ZHANG R, LIN XH, MA M, CHEN J, CHEN J et al. Periostin involved in the activated hepatic stellate cells-induced progression of residual hepatocellular carcinoma after sublethal heat treatment: its role and potential for therapeutic inhibition. J Transl Med 2018; 16: 302. https://doi.org/10.1186/ s12967-018-1676-3

[42] ZHANG R, YAO RR, LI JH, DONG G, MA M et al. Activated hepatic stellate cells secrete periostin to induce stem cell-like phenotype of residual hepatocellular carcinoma cells after heat treatment. Sci Rep 2017; 7: 2164. https://doi. org/10.1038/s41598-017-01177-6

[43] MA WQ, SUN XJ, ZHU Y, LIU NF. Metformin attenuates hyperlipidaemia-associated vascular calcification through antiferroptotic effects. Free Radic Biol Med 2021; 165: 229-242. https://doi.org/10.1016/j.freeradbiomed.2021.01.033

[44] NIELSEN SR, QUARANTA V, LINFORD A, EMEAGI P, RAINER C et al. Macrophage-secreted granulin supports pancreatic cancer metastasis by inducing liver fibrosis. Nat Cell Biol 2016; 18: 549-560. https://doi.org/10.1038/ncb3340
[45] CHEN G, NAKAMURA I, DHANASEKARAN R, IGUCHI E, TOLOSA EJ et al. Transcriptional Induction of Periostin by a Sulfatase 2-TGF $\beta 1$-SMAD Signaling Axis Mediates Tumor Angiogenesis in Hepatocellular Carcinoma. Cancer Res 2017; 77: 632-645. https://doi.org/10.1158/0008-5472.Can15-2556

[46] LIU Y, GAO F, SONG W. Periostin contributes to arsenic trioxide resistance in hepatocellular carcinoma cells under hypoxia. Biomed Pharmacother 2017; 88: 342-348. https:// doi.org/10.1016/j.biopha.2017.01.052

[47] CHEN K, LI Z, ZHANG M, WANG B, PENG T et al. miR876 Inhibits EMT and Liver Fibrosis via POSTN to Suppress Metastasis in Hepatocellular Carcinoma. Biomed Res Int 2020; 2020. https://doi.org/10.1155/2020/1964219

[48] JANG SY, PARK SY, LEE HW, CHOI YK,PARK KG et al. The Combination of Periostin Overexpression and Microvascular Invasion Is Related to a Poor Prognosis for Hepatocellular Carcinoma. Gut Liver 2016; 10: 948-954. https://doi. org/10.5009/gnl15481

[49] WEN Q, SHANG J, MISE SRL, BAI L. [Effects of periostin on hepatocellular carcinoma cells invasion, metastasis and prognosis]. Zhonghua gan zang bing za zhi 2019; 27: 766-771. https://doi.org/10.3760/cma.j.issn.1007-3418.2019.10.006

[50] ZENITANI M, NOJIRI T, HOSODA H, KIMURA T, UEHARA $S$ et al. Chemotherapy can promote liver metastasis by enhancing metastatic niche formation in mice. J Surg Res 2018; 224: 50-57. https://doi.org/10.1016/j.jss.2017.11.050

[51] KONGKAVITOON P, BUTTA P, SANPAVAT A, BHATTARAKOSOL P, TANGTANATAKUL P et al. Regulation of periostin expression by Notch signaling in hepatocytes and liver cancer cell lines. Biochem Biophys Res Commun 2018; 506: 739-745. https://doi.org/10.1016/j.bbrc.2018.10.144

[52] RIENER MO. [Diagnosis of tumours of the liver and the biliary tract: new tissue and serum markers]. Pathologe 2011; 32: 304-309. https://doi.org/10.1007/s00292-011-1467-6

[53] LV Y, WANG W, JIA WD, SUN QK, LI JS et al. High-level expression of periostin is closely related to metastatic potential and poor prognosis of hepatocellular carcinoma. Med Oncol 2013; 30: 385. https://doi.org/10.1007/s12032-012-0385-7

[54] FUJIMOTO K, KAWAGUCHI T, NAKASHIMA O, ONO J, OHTA $S$ et al. Periostin, a matrix protein, has potential as a novel serodiagnostic marker for cholangiocarcinoma. Oncol Rep 2011; 25: 1211-1216. https://doi.org/10.3892/ or.2011.1194

[55] UTISPAN K, THUWAJIT P, ABIKO Y, CHARNGKAEW $\mathrm{K}$, PAUPAIROJ A et al. Gene expression profiling of cholangiocarcinoma-derived fibroblast reveals alterations related to tumor progression and indicates periostin as a poor prognostic marker. Mol Cancer 2010; 9: 13. https://doi. org/10.1186/1476-4598-9-13

[56] RIENER MO, FRITZSCHE FR, SOLL C, PESTALOZZI BC, PROBST-HENSCH N et al. Expression of the extracellular matrix protein periostin in liver tumours and bile duct carcinomas. Histopathology 2010; 56: 600-606. https://doi. org/.1111/j.1365-2559.2010.03527.x 
[57] FU Q, CHENG J, ZHANG JD, ZHANG YL, CHEN XB et al. [Periostin regulated by let-7/miR-98 family mediates the apoptosis and epithelial-mesenchymal transition of colon cancer]. Zhonghua Zhong Liu Za Zhi 2019; 41: 573-579. https://doi.org/10.3760/cma.j.issn.0253-3766.2019.08.004

[58] SUEYAMA T, KAJIWARA Y, MOCHIZUKI S, SHIMAZAKI $\mathrm{H}$, SHINTO E et al.Periostin as a key molecule defining desmoplastic environment in colorectal cancer. Virchows Arch 2021; 478: 865-874. https://doi.org/10.1007/s00428-02002965-8

[59] OH HJ, BAE JM, WEN XY, CHO NY, KIM JH et al. Overexpression of POSTN in Tumor Stroma Is a Poor Prognostic Indicator of Colorectal Cancer. J Pathol Transl Med 2017; 51: 306-313. https://doi.org/10.4132/jptm.2017.01.19

[60] SHIOMI A, KUSUHARA M, SUGINO T, SUGIURA T, OHSHIMA $\mathrm{K}$ et al. Comprehensive genomic analysis contrasting primary colorectal cancer and matched liver metastases. Oncol Lett 2021; 21: 466. https://doi.org/10.3892/ ol.2021.12727

[61] RATAJCZAK-WIELGOMAS K, DZIEGIEL P. The role of periostin in neoplastic processes. Folia Histochem Cytobiol 2015; 53: 120-132. https://doi.org/10.5603/FHC.a2015.0014

[62] FIELD S, UYTTENHOVE C, STROOBANT V, CHEOU P, DONCKERS D et al. Novel highly specific anti-periostin antibodies uncover the functional importance of the fascilin 1-1 domain and highlight preferential expression of periostin in aggressive breast cancer. Int J Cancer 2016; 138: 19591970. https://doi.org/10.1002/ijc.29946

[63] GILLAN L, MATEI D, FISHMAN DA, GERBIN CS, KARLAN BY et al. Periostin secreted by epithelial ovarian carcinoma is a ligand for alpha(V)beta (3) and alpha(V)beta (5) integrins and promotes cell motility. Cancer Res 2002; 62: $5358-5364$.

[64] CHE J, SHEN WZ, DENG Y, DAI YH, LIAO YD et al. Effects of lentivirus-mediated silencing of Periostin on tumor microenvironment and bone metastasis via the integrin-signaling pathway in lung cancer. Life Sci 2017; 182: 10-21. https:// doi.org/10.1016/j.lfs.2017.05.030

[65] BAO S, OUYANG G, BAI X, HUANG Z, MA C et al. Periostin potently promotes metastatic growth of colon cancer by augmenting cell survival via the Akt/PKB pathway. Cancer Cell 2004; 5: 329-339. https://doi.org/10.1016/s15356108(04)00081-9

[66] KOH SJ, KIM JW, KIM BG, LEE KL, KIM DW et al. Matricellular protein periostin promotes colitis-associated colon tumorigenesis in mice. Carcinogenesis 2019; 40: 102-111. https://doi.org/10.1093/carcin/bgy120

[67] MA H, WANG J, ZHAO X, WU T, HUANG Z et al. Periostin Promotes Colorectal Tumorigenesis through Integrin-FAK-Src Pathway-Mediated YAP/TAZ Activation. Cell Rep 2020; 30: 793-806.e796. https://doi.org/10.1016/j.celrep.2019.12.075

[68] SHIMOYAMA Y, TAMAI K, SHIBUYA R, NAKAMURA M, MOCHIZUKI $M$ et al. Periostin attenuates tumor growth by inducing apoptosis in colitis-related colorectal cancer. Oncotarget 2018; 9: 20008-20017. https://doi.org/10.18632/oncotarget. 25026
[69] DONG D, ZHANG L, JIA L, JI W, WANG Z et al. Identification of Serum Periostin as a Potential Diagnostic and Prognostic Marker for Colorectal Cancer. Clin Lab 2018; 64: 973-981. https://doi.org/10.7754/Clin.Lab.2018.171225

[70] XU X, CHANG W, YUAN J, HAN X, TAN X et al. Periostin expression in intra-tumoral stromal cells is prognostic and predictive for colorectal carcinoma via creating a cancersupportive niche. Oncotarget 2016; 7: 798-813. https://doi. org/10.18632/oncotarget.5985

[71] SUNG PL, JAN YH, LIN SC, HUANG CC, LIN H et al. Periostin in tumor microenvironment is associated with poor prognosis and platinum resistance in epithelial ovarian carcinoma. Oncotarget 2016; 7: 4036-4047. https://doi. org/10.18632/oncotarget.6700

[72] XIAO ZM, WANG XY, WANG AM. Periostin induces chemoresistance in colon cancer cells through activation of the PI3K/Akt/survivin pathway. Biotechnol Appl Biochem 2015; 62: 401-406. https://doi.org/10.1002/bab.1193

[73] ZHENG X, LIU J, LI X, TIAN R, SHANG K et al. Angiogenesis is promoted by exosomal DPP4 derived from 5-fluorouracil-resistant colon cancer cells. Cancer Lett 2021; 497: 190-201. https://doi.org/10.1016/j.canlet.2020.10.009

[74] YOROZU A, YAMAMOTO E, NIINUMA T, TSUYADA A, MARUYAMA R et al. Upregulation of adipocyte enhancerbinding protein 1 in endothelial cells promotes tumor angiogenesis in colorectal cancer. Cancer Sci 2020; 111: 16311644. https://doi.org/10.1111/cas. 14360

[75] THONGCHOT S, SINGSUKSAWAT E, SUMRANSUB N, PONGPAIBUL A, TRAKARNSANGA A et al. Periostin regulates autophagy through integrin $\alpha 5 \beta 1$ or $\alpha 6 \beta 4$ and an AKT-dependent pathway in colorectal cancer cell migration. J Cell Mol Med 2020; 24: 12421-12432. https://doi. org/10.1111/jcmm.15756

[76] ERKAN M, KLEEFF J, GORBACHEVSKI A, REISER C, MITKUS T et al. Periostin creates a tumor-supportive microenvironment in the pancreas by sustaining fibrogenic stellate cell activity. Gastroenterology 2007; 132: 1447-1464. https://doi.org/10.1053/j.gastro.2007.01.031

[77] DE PALMA M, LEWIS CE. Macrophage regulation of tumor responses to anticancer therapies. Cancer Cell 2013; 23: 277-286. https://doi.org/10.1016/j.ccr.2013.02.013

[78] SHI C, WASHINGTON MK, CHATURVEDI R, DROSOS Y, REVETTA FL et al. Fibrogenesis in pancreatic cancer is a dynamic process regulated by macrophage-stellate cell interaction. Lab Invest 2014; 94: 409-421. https://doi.org/10.1038/ labinvest.2014.10

[79] PARK SY, PIAO Y, JEONG KJ, DONG J, DE GROOT JF. Periostin (POSTN) Regulates Tumor Resistance to Antiangiogenic Therapy in Glioma Models. Mol Cancer Ther 2016; 15: 2187-2197. https://doi.org/10.1158/1535-7163.Mct-150427

[80] KEKLIKOGLOU I, KADIOGLU E, BISSINGER S, LANGLOIS B, BELLOTTI A et al. Periostin Limits Tumor Response to VEGFA Inhibition. Cell Rep 2018; 22: 2530-2540. https://doi.org/10.1016/j.celrep.2018.02.035 
[81] KAKIZAKI Y, MAKINO N, TOZAWA T, HONDA T, MATSUDA A et al. Stromal Fibrosis and Expression of Matricellular Proteins Correlate with Histological Grade of Intraductal Papillary Mucinous Neoplasm of the Pancreas. Pancreas 2016; 45: 1145-1152. https://doi.org/10.1097/ mpa.0000000000000617

[82] DONG D, JIA L, ZHANG L, MA N, ZHANG A et al. Periostin and CA242 as potential diagnostic serum biomarkers complementing CA19.9 in detecting pancreatic cancer. Cancer Sci 2018; 109: 2841-2851. https://doi.org/10.1111/ cas. 13712

[83] PARK H, LEE Y, LEE H, KIM JW, HWANG JH et al. The prognostic significance of cancer-associated fibroblasts in pancreatic ductal adenocarcinoma. Tumour Biol 2017; 39: 1010428317718403. https://doi. org/10.1177/1010428317718403

[84] AGUILAR-CAZARES D, CHAVEZ-DOMINGUEZ R, CARLOS-REYES A, LOPEZ-CAMARILLO C, HERNANDEZ DE LA CRUZ ON et al. Contribution of Angiogenesis to Inflammation and Cancer. Front Oncol 2019; 9: 1399. https://doi.org/10.3389/fonc.2019.01399

[85] RIBATTI D, NICO B, CRIVELLATO E, ROCCARO AM, VACCA A. The history of the angiogenic switch concept. Leukemia 2007; 21: 44-52. https://doi.org/10.1038/ sj.leu.2404402

[86] NABA A, CLAUSER KR, MANI DR, CARR SA, HYNES RO. Quantitative proteomic profiling of the extracellular matrix of pancreatic islets during the angiogenic switch and insulinoma progression. Sci Rep 2017; 7: 40495. https://doi. org/10.1038/srep40495

[87] LIU Y, LI F, GAO F, XING L, QIN P et al. Periostin promotes tumor angiogenesis in pancreatic cancer via Erk/VEGF signaling. Oncotarget 2016; 7: 40148-40159. https://doi. org/10.18632/oncotarget.9512
[88] LIU Y, LI F, GAO F, XING L, QIN P et al. Periostin promotes the chemotherapy resistance to gemcitabine in pancreatic cancer. Tumour Biol 2016; 37: 15283-15291. https://doi. org/10.1007/s13277-016-5321-6

[89] SHEN YW, ZHOU YD, LUAN X, ZHANG WD. Blocking CTGF-Mediated Tumor-Stroma Interplay in Pancreatic Cancer. Trends Mol Med 2020; 26: 1064-1067. https://doi. org/10.1016/j.molmed.2020.08.005

[90] NEESSE A, BAUER CA, ÖHLUND D, LAUTH M, BUCHHOLZ $M$ et al. Stromal biology and therapy in pancreatic cancer: ready for clinical translation? Gut 2019; 68: 159-171. https://doi.org/10.1136/gutjnl-2018-316451

[91] OO KK, KAMOLHAN T, SONI A, THONGCHOT S, MITRPANT C et al. Development of an engineered peptide antagonist against periostin to overcome doxorubicin resistance in breast cancer. BMC Cancer 2021; 21: 65. https://doi. org/10.1186/s12885-020-07761-w

[92] STERZYŃSKA K, KAŹMIERCZAK D, KLEJEWSKI A, ŚWIERCZEWSKA M, WOJTOWICZ K et al. Expression of Osteoblast-Specific Factor 2 (OSF-2, Periostin) Is Associated with Drug Resistance in Ovarian Cancer Cell Lines. Int J Mol Sci 2019; 20. https://doi.org/10.3390/ijms20163927

[93] KIM CJ, YOSHIOKA N, TAMBE Y, KUSHIMA R, OKADA $\mathrm{Y}$ et al. Periostin is down-regulated in high grade human bladder cancers and suppresses in vitro cell invasiveness and in vivo metastasis of cancer cells. Int J Cancer 2005; 117: 51-58. https://doi.org/10.1002/ijc. 21120

[94] GIANCOTTI FG, RUOSLAHTI E. Integrin signaling. Science 1999; 285: 1028-1032. https://doi.org/10.1126/science.285.5430.1028

[95] LEE YJ, KIM IS, PARK SA, KIM Y, LEE JE et al. Periostinbinding DNA aptamer inhibits breast cancer growth and metastasis. Mol Ther 2013; 21: 1004-1013. https://doi. org/10.1038/mt.2013.30 